\title{
MOVIMENTO E RITMO \& JOGOS TEATRAIS NA FORMAÇÃO CONTINUADA DE PROFESSORES NO VALE DO ITAJAÍ/SC
}

\author{
Olívia Camboim Romano (FURB) ${ }^{1}$ \\ camboim.olivia@gmail.com \\ Ivana Vitória Deeke Fuhrmann (FURB) ${ }^{2}$ \\ ivacontemporaneo@hotmail.com
}

\section{INTRODUÇÃO}

Este estudo apresenta o trabalho de formação continuada efetuado com professoras da Educação Infantil da rede de ensino estadual e municipal no Vale do Itajaí/SC no período de 2011 a 2015 e foi desenvolvido dentro do projeto intitulado "O jogo teatral na escola" - vinculado ao Programa Institucional Arte na Escola (PIAE) Polo Universidade Regional de Blumenau (FURB). Cabe mencionar que tal projeto está em sua terceira edição e foi coordenado nos três primeiros anos pela primeira autora deste artigo e em 2014 passou a ser coordenado pela segunda autora deste artigo.

O PIAE é uma associação civil sem fins lucrativos que, desde 1989, qualifica, incentiva e reconhece o ensino da arte, por meio da formação continuada de professores da Educação Básica. Tem como premissa que a arte deve desenvolver habilidades perceptivas, capacidade reflexiva e incentivar a formação de uma consciência crítica. Na FURB o programa iniciou em 1993, coordenado pelas

\footnotetext{
${ }^{1}$ Graduada em Licenciatura em Artes Cênicas e Mestre em Teatro pela Universidade do Estado de Santa Catarina (UDESC). Doutoranda do Programa de Pós-Graduação em Artes Cênicas da Universidade da Federal da Bahia (PPGAC/UFBA). Professora efetiva da Universidade Regional de Blumenau (FURB) desde 2006. Autora do livro Uma arena no museu: reflexões sobre a primeira montagem de Brecht em Santa Catarina (Blumenau: Edifurb, 2010). Integra o G-PEC-Grupo de pesquisa em Encenação Contemporânea - Linha de Pesquisa Processos Educacionais em Artes Cênicas.

${ }^{2}$ Possui Licenciatura e Bacharelado em Dança pela Pontifícia Universidade Católica do Paraná. Especialização em Movimento Humano e Saúde e Mestrado em Educação pela Universidade Regional de Blumenau - FURB. É professora efetiva da FURB. Pesquisadora CNPQ (Teatro e Transdisciplinaridade - FURB). Editora da revista "O Teatro Transcende".

Revista "O Teatro Transcende" Departamento de Artes - CCEAL da FURB - ISSN 2236-6644 - Blumenau, Vol. 20, № 1, p. 53 - 73, 2015
} 
professoras Ma. Marilene de Lima Körting Schramm e Ma. Rozenei Maria Wilvert Cabral e atualmente conta com três projetos: "O jogo teatral na escola", "Formação Continuada" ${ }^{3}$ e "Midiateca" ${ }^{4}$ e várias professoras envolvidas: Ma. Lindamir Aparecida Rosa Junge, Ma. Marilene de Lima Körting Schramm, Ma. Melita Bona, Ma. Rozenei Maria Wilvert Cabral e as autoras deste estudo. Segundo Schramm e Cabral (2010, p. 19), a finalidade do PIAE "[...] é de fomentar a qualificação de processos educacionais em arte, com o propósito de ser agente de transformação e fonte de referência no ensino da arte, auxiliando professores, estudantes e demais interessados na área".

O PIAE tem atendido diversas cidades de Santa Catarina com os três projetos que desenvolve. Oferece oficinas e palestras para professoras das cidades de Blumenau, Gaspar, Indaial e Schroeder; integrantes do Programa de Educação Permanente da FURB, programa destinado aos idosos, professores, técnicoadministrativos e estudantes da FURB, especialmente dos cursos de Artes Visuais, Música, Pedagogia e Teatro e alunos do ensino médio da Escola Técnica do Vale do Itajaí (ETEVI) da FURB, participantes do Programa Institucional de Bolsa de Iniciação à Docência (PIBID) e do Plano Nacional de Formação de Professores da Educação Básica (PARFOR) presencial.

Colocando em foco o projeto "O jogo teatral na escola", o mesmo apresentou eixo inicial centrado na mediação teatral quando coordenado pela primeira autora deste artigo e posteriormente ampliou as oficinas abarcando também a área da dança/movimento com a entrada da segunda autora deste artigo no projeto.

\footnotetext{
3 “O objetivo do projeto [Formação Continuada] é qualificar professores de arte na educação infantil, ensino fundamental, médio e superior, com ações sistemáticas que proporcionem aprendizagem efetiva em arte e seu ensino, e subsidia a reflexão de práticas e processos educacionais" (SCHRAMM; CABRAL, 2010, p. 30).

4 "O projeto Midiateca, atualmente conta com aproximadamente 7.500 materiais educativos no acervo. Destaca a importância do uso desses materiais no processo ensino-aprendizagem de Artes Visuais, Música e Teatro. Focaliza a utilização de materiais de arte, como produto artístico, cultural, social e histórico" (SCHRAMM; CABRAL, 2010, p. 32). 
Podemos compreender a mediação teatral, no âmbito de projetos que visem à formação de público, como qualquer iniciativa que viabilize o acesso dos espectadores ao teatro, tanto o acesso físico, quanto o acesso linguístico. [...] O acesso linguístico, como o próprio termo sugere, opera nos terrenos da linguagem. E trata não apenas da promoção, do estímulo, mas especialmente da constituição do percurso relacional do espectador com a cena teatral, da conquista de sua autonomia crítica e criativa. [...] um projeto de formação de espectadores visa não apenas a facilitação do acesso físico, mas também, e principalmente, a do acesso linguístico, pois quer trabalhar com as individualidades, com as subjetividades, com as conquistas efetivadas por cada espectador no processo em curso (DESGRANGES, 2008, p. 76-77).

O projeto se fez necessário uma vez que foi identificada a carência de professores habilitados para atuarem na disciplina de Artes e, especialmente, com as áreas de dança e teatro; escassa formação continuada na área; desconhecimento da comunidade escolar e universitária dos principais elementos da linguagem teatral; baixa participação de professores e escolares em eventos artísticos e culturais de Blumenau e região.

\section{OS PRIMEIROS PASSOS DO PROJETO: OS JOGOS TEATRAIS}

Nos primeiros três anos de realização do projeto, entre 2011 e 2014, foram oferecidas oficinas de jogos teatrais e improvisação de curta duração para professores de Blumenau, Gaspar, Indaial e Schroeder e para estudantes do Ensino Médio de Blumenau $^{5}$. A maior parte das oficinas foram ofertadas nas dependências do Curso de Teatro do Departamento de Artes da FURB; mas algumas oficinas com professoras de Educação Infantil foram realizadas na cidade de Gaspar/SC .

\footnotetext{
5 Também foram ofertadas oficinas eventuais para os seguintes públicos: integrantes do Programa de Educação Permanente da FURB, programa destinado aos idosos; professores, técnico-administrativos e estudantes da FURB, especialmente, dos cursos de Artes Visuais, Música, Pedagogia e Teatro, participantes do Programa Institucional de Bolsa de Iniciação à Docência (Pibid) e do Plano Nacional de Formação de Professores da Educação Básica (PARFOR) presencial.
}

6 Localizada a 16 km de distância de Blumenau/SC. 
Em 2011 foram atingidas diretamente 202 pessoas, dentre elas 74 professoras da Educação Básica, e indiretamente cerca de 3.784 pessoas. Em 2012 foram atingidas diretamente cerca de 488 pessoas, dentre elas 250, vinculadas à Educação Básica do setor público (municipal estadual ou federal), e indiretamente aproximadamente 12.102 pessoas. Em 2013 foram atingidas diretamente 218 pessoas, dentre as quais 135 são professores da rede pública de ensino, e indiretamente cerca de 9.997 pessoas. Para a quantificação foi considerado público direto os participantes das oficinas e/ou espectadores presentes nas apresentações públicas (fruto das oficinas de longa duração). O público indireto foi considerado os atingidos pelos desdobramentos do projeto, os alunos dos professores participantes das oficinas e a quantidade de pessoas que curtirem as ações no facebook e responderem aos convites do projeto.

Todas as oficinas de jogos teatrais e improvisação estiveram embasadas nos trabalhos da diretora norte-americana Viola Spolin (1906-1994) e nas proposições de Augusto Boal (1931-2009). Os jogos teatrais de Spolin e os jogos para atores e nãoatores de Boal destacam-se ultimamente no Brasil como algumas das principais correntes metodológicas do ensino do teatro. Tais metodologias podem ser utilizadas tanto no contexto educacional como na preparação dos atores. Portanto, os jogos teatrais e a improvisação podem ser praticados por todos que desejam se expressar por meio do teatro.

Dentre os jogos realizados nas oficinas, baseados nos jogos teatrais de Spolin, que contribuem, sobretudo, para focalização na resolução de um problema, destacamse: a) números rápidos, no qual os jogadores, organizados em um semicírculo e numerados sucessivamente, devem conectar pensamento, gesto e voz. Assim, o jogador número 01, na ponta do semicírculo, inicia o jogo chamando pelo número, olhando e apontando com o dedo outro jogador. O jogador cujo número foi chamado responde imediatamente apontando com o dedo outro jogador e dizendo o número que lhe corresponde no semicírculo, e assim por diante. O jogador que se engana muda sua posição no semicírculo e passa a ser o jogador número 01; portanto, o Revista "O Teatro Transcende" Departamento de Artes - CCEAL da FURB - ISSN 2236-6644 - Blumenau, Vol. 20, N 1, p. 53 - 73, 2015 
número dos jogadores pode mudar frequentemente, pois todos mudam suas posições quando um deles se equivoca (2008, p. 57); b) o jogo do nó humano, em que os jogadores, organizados em círculo e com as mãos dadas (mão direita por cima da mão do colega e mão esquerda por baixo da mão do outro colega), são conduzidos pela coordenadora para realizarem a "amarração" do grupo como um nó humano até que ninguém consiga se movimentar; e, em seguida, o grupo começa a se desenrolar a partir dessa posição, sem soltar as mãos, até que o círculo volte à posição inicial (2008, p. 61); entre outros jogos.

Dentre os jogos praticados nas oficinas, pautados nos jogos de Boal, que contribuem para desinibição, aquecimento e remoção de distrações externas, destacam-se: a) o jogo "Bom dia!" (ou "Boa tarde!" ou "Boa noite!", de acordo com o turno em que é realizado), com o objetivo de promover a apresentação dos participantes, no início da jornada de trabalho, eles são solicitados a cumprimentar com sua mão direita um colega e só largar da mão dele quando sua mão esquerda já estiver de mão dada com outro colega até que todos os participantes se cumprimentem e formem uma rede de apertos de mão em que ninguém fica sem estar de mãos de dados com pelo menos um colega (2007, p. 118); b) o jogo do balão como prolongamento do corpo, em que os participantes da oficina ficam reunidos no centro da sala e a coordenadora, aos poucos, vai jogando um balão de cada vez na roda até que cada jogador tenha seu próprio balão; com movimentos de "flutuação", os balões devem ser mantidos no alto com várias partes de seus corpos, utilizando o mínimo possível as mãos (2007, p. 99); c) o jogo da estátua de sal, que consiste num pega-pega tradicional no qual aquele que for tocado pelo pegador se converte em estátua de sal (com as pernas abertas) e só será liberado se alguém livre passar por baixo de suas pernas (2007, p. 117); d) jogo do espelho, em que os jogadores em duplas são distribuídos em duas filas ( $\mathrm{A}$ e B) e devem refletir os movimentos e gestos do parceiro da dupla - após o tempo definido pela coordenadora, as posições são invertidas (2007, p. 172); e) o jogo da máquina de ritmos, no qual um dos jogadores vai até o centro da sala e imagina que é a peça de engrenagem de uma máquina complexa; o jogador deve fazer um movimento rítmico com seu corpo e, ao mesmo Revista "O Teatro Transcende" Departamento de Artes - CCEAL da FURB - ISSN 2236-6644 - Blumenau, Vol. 20, № 1, p. 53 - 73, 2015 
tempo, o som dessa peça. Os demais jogadores, um de cada vez e aos poucos, acrescentam com movimento e som uma peça complementar da engrenagem dessa máquina, até que todo o grupo esteja integrado em uma mesma máquina e a coordenadora possa instruir a equipe para acelerar e desacelerar seu funcionamento (2007, p. 129); f) o jogo ninguém com ninguém, no qual um dos jogadores (designado como líder) indica em voz alta quais partes dos corpos dos demais jogadores (organizados em duplas) devem se tocar, por exemplo: cabeça com cabeça, pé direito com cotovelo esquerdo, mão na cintura. Os contatos indicados devem são cumulativos e o líder só cessa as indicações quando já não for possível manter os contatos corporais anteriores com novas instruções; nesse momento, o líder grita "ninguém com ninguém" e os jogadores formam novas duplas e aquele que ficar sem parceiro é o novo líder. Tal jogo, para além do aquecimento, contribui para integração dos participantes e vivência do papel de liderança com responsabilidade, proposição de desafios e, ao mesmo tempo, com respeito diante das particularidades dos integrantes da equipe (2007, p. 110); g) o jogo o líder designado, em que os jogadores são dispostos em círculo, sentados de olhos fechados, e a coordenadora toca o líder designado por ela e, em seguida, todos, de olhos abertos, devem tentar descobrir quem é o líder. $\mathrm{O}$ jogo se repete três vezes e contribui para que os participantes reflitam sobre o papel do líder e questionem as instruções recebidas para que não obedeçam mecanicamente (2007, p. 210); entre outros jogos e improvisações.

Nas oficinas de jogos teatrais, o protocolo ${ }^{7}$ foi um dos principais instrumentos de avaliação. Para a confecção dos protocolos, os participantes recebiam uma folha de papel em branco, diferentes lápis e canetas coloridas, papéis coloridos com diversas texturas, tesoura e cola branca. Assim, no final de cada jornada de trabalho, os jogadores eram estimulados a confeccionarem um relatório lúdico (com relatos, desenhos, poesias, palavras soltas, etc.), para ser socializado, em roda, oralmente.

\footnotetext{
7 o protocolo, "instrumento interno de reflexão coletiva" (PUPO, 2005, p. 45), foi um dos procedimentos metodológicos utilizados pelo dramaturgo e encenador alemão Bertolt Brecht (1898-1956), no momento em que ele formulava sua proposição estético-pedagógica. 
Segundo Leite,

[...] Escrever e dizer protocolos passa também a fazer parte do jogo, embora num momento distinto e não simultâneo com o jogo teatral. Para cada um dos jogadores é um dos aspectos de cada sessão que chama a atenção. Criase uma expectativa quando alguém vai dizer o seu protocolo porque há um diálogo entre eles. Esse olhar do 'outro' alimenta o 'eu' de cada jogador [...] (LEITE, 2009, p. 300-301).

Nos protocolos das oficinas de jogos teatrais, palavras como diversão e interação são recorrentes - conforme ilustra a Imagem 1. Além disso, as respostas às oficinas de jogos teatrais ao longo desses anos foram bastante positivas, como ilustra 0 seguinte depoimento de uma professora da Ed. Infantil de Indaial/SC: "Foi muito legal o encontro de hoje, pois me ajuda profissionalmente e principalmente pessoalmente me fazendo perder um pouco da minha timidez. Outro ponto é perceber o quanto foi importante estimular os nossos sentidos e o quanto eles fazem falta" (Blumenau, 19/06/2012).

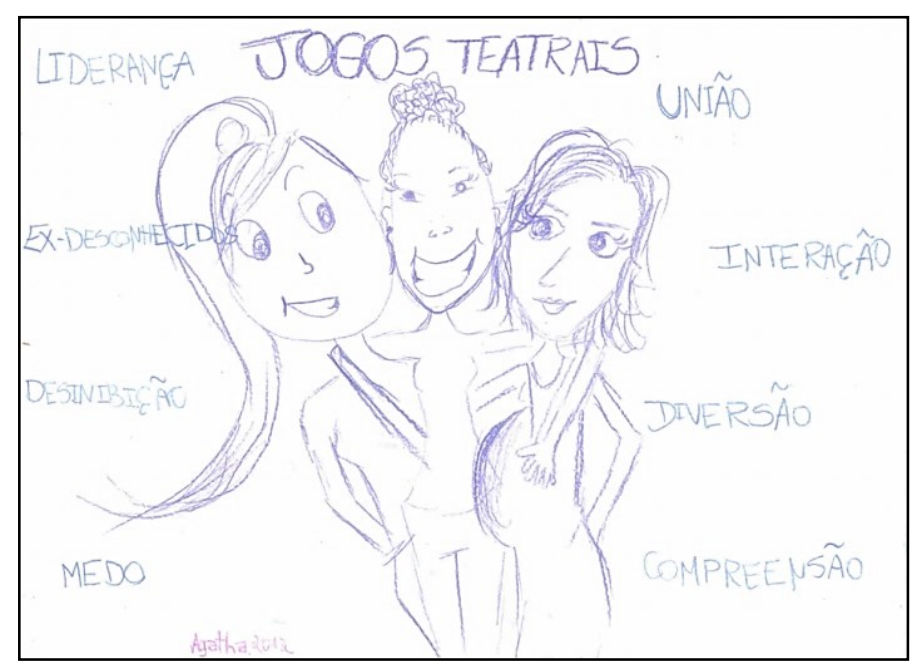

Imagem 1 - Protocolo de estudante da FURB do Curso de Pedagogia (participante do PIBID). Blumenau, $19 / 07 / 2012$

Esses protocolos contribuíram para que os integrantes das oficinas revelassem seus pontos de vista, promoveram a avaliação em grupo sobre o processo de ensinoaprendizagem, permitiram verificar o que os participantes aprenderam com as Revista "O Teatro Transcende" Departamento de Artes - CCEAL da FURB - ISSN 2236-6644 - Blumenau, Vol. 20, № 1, p. 53 - 73, 2015 
oficinas, seu aproveitando, e oportunizam repensar o planejamento dos conteúdos das próximas oficinas.

De 2011 a 2014, as oficinas abordaram, em linhas gerais, os elementos básicos da linguagem teatral; o conceito e a prática dos "jogos teatrais"; a importância da brincadeira, do prazer aliado ao conhecimento no ensino do teatro na escola; e a elaboração de protocolos de avaliação como instrumento de avaliação das atividades.

\section{UM NOVO OLHAR: A DANÇA E AS OFICINAS DE IDENTIDADE E PERCUSSÃO CORPORAL}

A partir de 2014 a dança começou a integrar o conteúdo das oficinas ministradas dentro do projeto "O jogo teatral na escola" oferecendo atividades de "Identidade Corporal" e "Percussão Corporal". Foi oportunizado aos participantes, no papel de "professores alunos", vivências por intermédio do movimento para que criassem relações com sua própria identidade corporal e sons promovidos com o próprio corpo e desenvolvessem consciência corporal. A forma como cada qual utiliza o seu corpo diz muito do caráter, da emoção, sensibilidade, tabus constituindo a identidade. E tais experiências vivenciadas pelos professores podem posteriormente ser trabalhadas com as crianças - seus alunos.

Assim sendo, foi aliado ao trabalho já desenvolvido atividades de dança dentro do mesmo espírito de "jogos teatrais" - pautados no trabalho da diretora norteamericana Viola Spolin uma vez que,

A técnica de Jogos Teatrais propõe uma aprendizagem não verbal, onde o aluno reúne os seus próprios dados, a partir de uma experimentação direta. Através do processo de solução de problemas, ele conquista o conhecimento da matéria (KOUDELA, 1998, p. 64). 
O público alvo das oficinas de "Identidade Corporal" foram 50 professoras de Educação Infantil da cidade de Indaial/SC que está localizada próximo de Blumenau e as professoras vieram até a FURB para participar da oficina que contou com uma carga horária de 3 (três) h/a. As mesmas foram divididas em dois grupos que trabalharam em dias diferentes para melhor andamento das atividades. As atividades foram desenvolvidas nos dias 26/03/2014 e 07/04/2014.

No caso da "Percussão corporal" as atividades foram desenvolvidas nos dias 8/10/2014 com 23 professoras da cidade de Indaial/SC e no dia 11/11/2014 com 26 professoras de Jaraguá do Sul/SC que também se situa próximo de Blumenau. A carga horária foi igualmente de 3(três) h/a e as atividades desenvolvidas igualmente na FURB.

Ambas as oficinas tiveram como objetivo capacitar, de maneira inicial, tais professoras para mediarem o contato de seus alunos com as artes cênicas e neste caso em especial, com o movimento, tendo a dança como ferramenta de trabalho. Sabe-se que a carga horária é mínima, no entanto esclarece-se que a formação é continuada e assim sendo novas oficinas vão sendo ofertadas em sequência. Explica-se ainda, que o mesmo grupo de professoras já participou de vários encontros anteriores onde trabalharam com "jogos teatrais".

Faz-se necessário mencionar que o "reconhecimento da arte como área de conhecimento a ser trabalhada nas escolas foi legalmente introduzido pela LDB (Lei de Diretrizes e Bases) 9394/96, em 1997, e esse processo foi coroado em âmbito nacional com a inclusão da dança nos Parâmetros Curriculares Nacionais (PCNs)" (MARQUES, 2006, p. 101). No entanto, essa não é a prática realizada na maioria das escolas do estado de Santa Catarina e vale mencionar que o estado ainda não possui nenhuma graduação em Dança. Além disso, na rede pública de ensino no Vale do Itajaí prevalece em muitas unidades escolares o ensino polivalente das linguagens artísticas, conforme Revista "O Teatro Transcende" Departamento de Artes - CCEAL da FURB - ISSN 2236-6644 - Blumenau, Vol. 20, № 1, p. 53 - 73, 2015 
instituído pela antiga Lei 5.692/71 (LDBEN/71), em que um mesmo professor é responsável pelo ensino de conteúdos de música, artes visuais, teatro e dança. A região de Blumenau também é carente de professores licenciados em Teatro para atuarem na disciplina Arte, uma vez que a única Universidade da região, a FURB, que oferta cursos superiores em Teatro desde 1995, passou quase 10 (dez) anos sem abrir uma turma de licenciatura (de 2004 a 2013). Dentre as diferentes razões da não abertura da licenciatura em Teatro em Blumenau nesses anos, podemos mencionar: a resistência, durante anos, de parte do corpo docente em ofertar licenciatura em decorrência da "preferência" dos discentes pelo bacharelado; pelo alto custo das mensalidades, uma vez que a instituição é pública (Autarquia Municipal), mas não é gratuita, entre outros fatores.

Assim sendo, a dança, o movimento corporal, é bastante distante dos alunos bem como dos próprios professores uma vez que não apresentam qualificação para tal e não vivenciarem referida realidade mesmo quando alunos. Marques (2006) desenvolve seus estudos abordando e defendendo a inclusão da dança na escola de ensino formal. No entanto, pondera sobre as dificuldades de incluir a disciplina dança no currículo obrigatório, afirmando que, atualmente, os professores da referida disciplina nas escolas não possuem a qualificação necessária para tal.

A questão foi verificada antes de iniciar as atividades práticas onde o público alvo, em sua maioria professoras formadas em Pedagogia, respondeu um questionário. As perguntas foram elaboradas a fim de se conseguir montar um perfil dos professores que fazem a formação, ou seja, a oficina, e o público que por eles é atingido. As perguntas abordaram a escolaridade, atividade artística que participa, com quais turmas trabalham, disciplinas que lecionam, qual a média de alunos por sala bem como qual a relação com as Artes Cênicas (dança e teatro). Conhecendo o perfil do público alvo é possível melhorar a interação desse público com a dança e artes em geral e também aumentar a demanda de participação das referidas áreas em nossa região.

Revista "O Teatro Transcende" Departamento de Artes - CCEAL da FURB - ISSN 2236-6644 - Blumenau, Vol. 20, № 1, p. 53 - 73, 2015 
Quando interrogadas sobre qual a sua relação com as Artes Cênicas, as respostas demonstraram que a adesão às práticas culturais é bastante limitada e dessa forma concordamos com Pierre Bourdieu e Alain Darbel (2003), que no livro Amor pela Arte, esclarecem que a cultura não é um privilégio natural e de que a prática cultural não é um dom ou uma questão de sensibilidade inata ligada à emoção, pois existem condições sociais que tornam possível o usufruto desse privilégio. Dessa forma, entendemos que por vezes as pessoas não dançam ou não compreendem seu corpo, pelo fato de tal questão não fazer parte do seu estilo de vida, de sua cultura familiar e local. Vale lembrar que Santa Catarina está localizada na região sul do Brasil, colonizada em sua maioria por europeus e assim sendo é uma região um pouco mais séria e formal e tal fato reflete no estilo de vida de seus habitantes.

Considerando tais questões foram oferecidas para as professoras em questão aulas práticas a fim de que sentissem com seu próprio corpo o que a dança poderia oferecer. Trabalhando a consciência corporal e utilizando vários ritmos musicais os então "professores alunos" foram obrigados a sair de sua "zona de conforto" e vivenciar o movimento. De início percebeu-se certo receio, insegurança e medo da exposição, o próprio fato de tocar no corpo do outro era constrangedor. Para mediar e facilitar tal processo foram utilizados "balões" na oficina de "Identidade Corporal" e "garrafas pet" nas oficinas de "Percussão Corporal" como elemento cênico nas atividades propostas.

A intenção era fazer com que as professoras passassem a compreender que a vida é feita de movimento e que elas poderiam aproximar o mesmo das crianças nas escolas onde trabalham. De uma forma simples e bastante lúdica os então "professores alunos" foram vivenciando alongamentos, passos de dança, movimentos de criação pessoal, matrizes corporais de criação coletiva. 
Em ambas as oficinas os exercícios de início eram mais formais onde o aluno segue o exemplo do professor. Na sequência foram evoluindo e criações coletivas iam surgindo de forma que a improvisação passou a se fazer presente. Segundo Ryngaert (2009, p. 90-91), a improvisação “[...] provoca o sujeito a reagir, seja no interior da proposta que Ihe é feita, seja em torno da proposta, explorando amplamente a zona que se desenha para ele, segundo o modo como sua imaginação é convocada".

Dessa forma, compreende-se que a improvisação nas situações de formação de professores é uma ferramenta de trabalho muito útil oferecendo ao praticante experiências no processo criativo, onde o mesmo atua como autor e executor do movimento. A mesma possibilita a entrada do lúdico, o resgate do movimento próprio, o descobrimento do corpo por intermédio da imaginação, da inventividade ampliando as relações entre o universo exterior e o interior.

Para Bourdieu (2004, p. 218-219), “[...] uma prática corporal [...] [se aprende], por uma comunicação silenciosa, prática, corpo a corpo". Assim, a disposição para a dança não é incorporada de forma mecânica, constitui-se, porém, o resultado da ação sistematizada de incutir princípios coerentes, que acontece no âmbito da prática para a prática. Professores recebendo formação para apresentarem para seus alunos o que "O jogo teatral na escola" pode oferecer.

Por tais questões enfatiza-se a necessidade do então "professor aluno" vivenciar o movimento corporal e não apenas ir para a oficina e ouvir o que pode ser feito com o seu aluno em sala de aula, mas realmente fazer, "sentir na pele" para posteriormente adaptar as atividades para sua realidade em sala de aula. Ainda segundo Bourdieu (1998, p. 74 - 75 - grifos do autor), todo esse processo, 
[...] exige uma incorporação que, enquanto pressupõe um trabalho de inculcação e de assimilação, custa tempo que deve ser investido pessoalmente pelo investidor, [...] essa incorporação não pode efetuar-se por procuração. Sendo pessoal, o trabalho de aquisição é um trabalho do "sujeito" sobre si mesmo [...] Esse capital "pessoal" não pode ser transmitido instantaneamente (diferentemente do dinheiro, do título de propriedade ou mesmo do título de nobreza) por doação ou transmissão hereditária, por compra ou troca.

A dança exige entrega e o desenvolvimento da habilidade está vinculado à prática da atividade e pode oferecer grandes descobertas. Segundo Marques (2006, p.134), "a dança experimentada concretamente possibilita uma ampliação do vocabulário corporal que pode também permitir uma outra forma de se apropriarem de seus corpos, de estarem no mundo e de se comunicarem com ele".

Assim sendo, a dança soma-se ao contexto dos jogos teatrais e oferece a possibilidade de desdobramentos acerca da cultura local e global, um entendimento da construção da identidade corporal, uma vez que, os jogos "são úteis ao ensinar tópicos de outras áreas do currículo" (SPOLIN, 2008, p. 312), tais como: artes visuais, ciências, cinema, esportes, estudos do ambiente, estudos sociais, história, literatura, música, produção de texto, rádio, teatro, TV, entre outros.

Com a oficina de "Identidade Corporal" foi atingido um público indireto de 1.019 pessoas e na oficina de "Percussão Corporal" foi atingido um público indireto de 1.841. Assim sendo, o público total atingido foi de 2.959 pessoas. Para a quantificação, foi considerado público direto os participantes das oficinas e público indireto se constituiu os atingidos pelos desdobramentos do projeto, os alunos dos professores participantes das oficinas. 
Há de se considerar ainda que o projeto "O jogo teatral na escola" possui uma página no Facebook: https://www.facebook.com/jogoteatralnaescola, e assim sendo, de uma maneira virtual, também existe um público atingido.

Para avaliar o alcance das oficinas, como instrumento de pesquisa, além do questionário já mencionado, uma segunda ferramenta de verificação foi acionada ao término da oficina. Esta por sua vez teve por objetivo proporcionar aos "professores alunos" uma reflexão sobre seu envolvimento, atuação e sensações acerca da oficina, ou seja, o seu processo de inculcação da sua identidade e percussão corporal. Além disso, possibilitou a verificação de conteúdos que podem ser transpostos para a sala de aula em sua prática como professor.

As professoras receberam uma folha de papel onde deveriam escrever um depoimento acerca do trabalho desenvolvido. Dessa forma, foi possível conhecer o ponto de vista de cada participante sobre o que foi trabalhado.

Na sequência seguem alguns fragmentos de depoimentos das participantes: "O corpo em movimento embasa a importância de se trabalhar o conjunto corporal, de forma lúdica e atrativa para o participante"; "É muito rica a aula de percussão corporal. Podemos usar até materiais recicláveis para enriquecer os movimentos"; "Basta usar a criatividade para transformar os movimentos em coreografia, são experiências que as crianças irão adorar"; "A formação foi bastante produtiva, vários movimentos podem ser adaptados para educação infantil, a professora é muito dinâmica e propôs uma adaptação para sala de aula para cada atividade que realizamos"; "Adorei essa tarde. Conheci movimentos que podemos trabalhar com a educação infantil, é brincando que a criança aprende"; "Foi maravilhoso explorar os sons do meu corpo, sentir como posso manipular ele em meu favor, isso fez-me refletir como devo e posso atuar em sala de aula com meus alunos estes movimentos e sensações"; "Foi muito divertido poder dançar e fazer música com instrumentos Revista "O Teatro Transcende" Departamento de Artes - CCEAL da FURB - ISSN 2236-6644 - Blumenau, Vol. 20, No 1, p. 53 - 73, 2015 
alternativos como uma garrafa PET, e saber que cada som, até mesmo umas batidas no bumbum pode estar produzindo música para a criança"; "Não esperava uma aula tão divertida"; "Gostei muito de trabalhar com balões; "Entendi que posso fazer o que quiser se me dedicar"; "Preciso me movimentar mais contagiando as crianças e chamar o movimento para elas".

Percebemos que as atividades propostas incentivaram as professoras envolvidas servindo para alavancar a inserção do movimento nas atividades diárias das mesmas junto as suas atividades de trabalho, bem como, proporcionaram um maior conhecimento sobre o corpo das mesmas.

De maneira geral nos depoimentos das professoras predominaram relatos que trouxeram a tona sensações como a diversidade, a percepção, o conhecimento, o companheirismo, a desinibição, a diversão, a interação, a liberdade, o descobrimento do movimento individual e do trabalho em grupo.

MOVIMENTO E RITMO EM FOCO:

Chegamos em 2015. Até o presente momento foram oferecidas duas oficinas de "Movimento e Ritmo" oportunizando assim a formação continuada tendo o movimento como foco. As atividades foram desenvolvidas nos dias 25/03/2015 e 13/04/2015, ambos os grupos formados por 27 professoras da cidade de Indaial/SC. A carga horária foi de 3 (três) h/a com cada grupo e as atividades foram desenvolvidas na FURB. 
O objetivo foi trabalhar o alongamento e consciência corporal, passos de dança de variados ritmos, jogos rítmicos com elementos cênicos onde utilizamos pedaços de "tule", jogos de ação e reação, bem como exercícios de respiração.

Como já mencionado nas oficinas anteriores questionários foram feitos para termos o conhecimento da formação das participantes e como instrumento para análise dos dados as professoras ao final da oficina escreveram em um papel um depoimento.

\begin{abstract}
Esta oficina me trouxe a infância, pois eu amava danças mesmo que, muitas vezes estabanada, mas era o máximo. Acredito que aprendi muito e posso tirar muito proveito para minhas aulas e planejamentos. Foi uma aula super animada e produtiva. (Depoimento Professora 27).
\end{abstract}

Assim o presente trabalho discute especialmente sob a necessidade de ofertar ao educando diferentes experiências e tomou o movimento corporal como linguagem artística capaz de assegurar o direito dos participantes das oficinas de se inserirem em um espaço ludo-pedagógico e de se manifestarem por meio da arte oportunizando assim a formação continuada dos professores.

Em 2015, até o presente momento, o público direto atingido foi de 54 professoras e o público indireto totalizou 2.443. Conforme anteriormente já mencionado para a quantificação, foi considerado público direto os participantes das oficinas e público indireto os alunos dos professores participantes das oficinas.

Percebemos que as oficinas realmente atingem as professoras e como uma mudança de conduta pode oportunizar aos alunos das mesmas significativas construções conforme observamos nos depoimentos: 
Aprendi muito com a aula de dança, deveríamos ter sempre, pois somos professoras e muitas vezes a ansiedade de realizar algum projeto toma conta de nós, e esses exercícios de dança, movimento e relaxamento não são apenas algo que podemos levar par a Unidade onde atuamos e sim o que devemos fazer é trazer mais para nossa vida e nossa rotina. Foi uma tarde divertida, o que mais me chamou a atenção foi de como é fácil colocar a música no nosso dia a dia, como podemos introduzir movimentos na sala com as crianças, desenvolver a atenção e concentração de maneira divertida com os nossos alunos. (Depoimento Professora 27).

Essa oficina foi muito proveitosa, pois além de relembrar ritmos de dança, a interação entre as colegas que quase não vimos ou temos pouco contato é extremamente importante, porque deixamos um pouco de nós e levamos um pouco de cada um. Sem contar que podemos aplicar nas atividades com os pequenos. (Depoimento Professora 3).

De acordo com a Proposta Curricular de Santa Catarina para que o futuro professor na Educação Infantil possa realmente realizar um bom trabalho em ensino da arte, é fundamental que, dentre outras questões, "vivencie atividades artísticas experimentando variados materiais e suportes" (SANTA Catarina, 1998, p. 146). Muitas vezes o contato com a arte não faz parte do dia a dia tanto do público docente quanto discente. Entende-se que a escola pode vir a suprir, em parte, tal lacuna e para tanto os professores necessitam estar habilitados.

Concordamos com Bourdieu (2004), que o agente social não é um indivíduo plenamente consciente de suas motivações, cujas ações visariam a fins explícitos, ou seja, por vezes, as pessoas acreditam estar agindo naturalmente quando na verdade suas ações estão de acordo com o modelo do que pensam ser mais indicado para a posição que ocupam. Assim, ainda para o autor, às diferentes posições no espaço social correspondem estilos de vida diferenciados. As práticas e as propriedades constituem uma expressão sistemática das condições de existência - o que é denominado como estilo de vida, porque é produto de um operador prático, o habitus. 
Considera-se o habitus, definido por Bourdieu (2004, p. 26), como "[...] um sistema de esquemas [disposições] adquiridos que funciona no nível prático como categorias de percepção e apreciação, ou como princípios de classificação e simultaneamente como princípios organizadores da ação".

\begin{abstract}
A oficina de hoje fez pensar e repensar na importância de conhecer e sentir cada parte do corpo, de ter o movimento no ritmo correto e estimular sempre a coordenação. É importante nos movimentar, mas ainda ter a coordenação e ritmo para tais execuções. (Depoimento Professora 7).
\end{abstract}

Dessa maneira os princípios organizadores da ação se estabelecem de uma forma mais ampla e profunda possibilitando maior conhecimento do corpo e consequentemente da construção corporal. A consciência corporal passa a fazer parte do planejamento de aula do corpo docente. É notório que o caminho não é fácil e exige determinação:

Pessoalmente tive dificuldades em fazer passos, movimentar os braços e as pernas no ritmo. Como professora vejo o lado bom disso tudo, pois acredito que as crianças terão as mesmas dificuldades e isso me possibilita a ir buscar alternativas em ajuda-las nessas dificuldades e a entendê-las melhor. (Depoimento Professora 10).

Mesmo diante das dificuldades percebeu-se que as 54 professoras de Indaial, em seus depoimentos, validaram o trabalho desenvolvido na oficina e conseguiram estabelecer relações com a prática docente de cada qual. Entende-se que as vivências estão possibilitando uma formação prazerosa, despertando o gosto pelo movimento. 


\section{ALGUMAS CONSIDERAÇÕES:}

Compreendemos que a vivência de jogos teatrais e oficinas que trabalham com a dança e o movimento estão proporcionando uma formação prazerosa para as professoras que participam do projeto; além disso, estão incentivando a frequência dos participantes em eventos de Teatro e Dança e contribuindo com a formação de plateia em Blumenau e região. Entendemos que vários mecanismos são acionados para a compreensão e construção da identidade corporal e cultural.

A possibilidade de ter acesso ao aprendizado dentro da área das artes cênicas abarca a trajetória individual de cada qual que perpassa diversos capitais como o econômico, escolar, cultural, social e simbólico envolvendo o estilo de vida. O projeto "O jogo teatral na escola" oferece novas possibilidades para os professores e os mesmos podem repassar tal conhecimento para seus alunos. Identificamos entre os professores participantes das oficinas aumento significativo de conhecimento relativo ao teatro e à dança, troca de experiência com outros professores e vivência de outras metodologias de ensino e instrumentos de avaliação.

Participar de atividades artísticas e culturais, onde a pessoa precisa interagir e se expor não é algo que nasce espontaneamente, é instalado, inculcado por intermédio de várias ações e mobilizações que podem germinar na família e se fortalecer nas instituições de ensino, ou seja, na escola. E, para tanto, os professores necessitam estar habilitados a fim de receber a demanda. A inculcação das atividades artísticas e sua interdependência com as diversas mobilizações, como por exemplo, a formação continuada dos professores se constrói no decorrer do tempo, ou seja, estão em jogo o antes (a bagagem pessoal de cada professora), as condições de origem (o envolvimento prévio com a área das artes cênicas) e os objetivos que almeja alcançar. Pretende-se que a atividade vivenciada não seja estanque e que cada professora reverbere em suas atividades em sala de aula buscando o incremento educacional e Revista "O Teatro Transcende" Departamento de Artes - CCEAL da FURB - ISSN 2236-6644 - Blumenau, Vol. 20, No 1, p. 53 - 73, 2015 
irradiando o conhecimento para seus alunos que compreendem o público indireto do estudo; pois, certamente, o projeto tem instrumentalizado e capacitado os professores participantes para mediarem o contato dos estudantes com as artes cênicas.

\section{REFERÊNCIAS:}

BOAL, Augusto. Jogos para atores e não atores. - 10 ed. rev. e ampliada. - Rio de Janeiro: Civilização Brasileira, 2007.

BOURDIEU, Pierre; Alain, DARBEL. 0 amor pela arte: os museus de arte na Europa e seu público. São Paulo: Editora da Universidade de São Paulo: Zouk, 2003.

BOURDIEU, Pierre. Coisas Ditas. São Paulo: Brasiliense, 2004.

Os três estados do capital cultural. In: NOGUEIRA, Maria Alice; CATANI, Afrânio Mendes (Orgs.). Escritos de educação. Petrópolis, RJ: Vozes, 1998. p. 71- 79

DESGRANGES, Flávio. Mediação Teatral: anotações sobre o Projeto Formação de Público. Urdimento - Revista de Estudos em Artes Cênicas/Universidade do Estado de Santa Catarina. Programa de Pós-Graduação em Teatro. - Vol 1, n.10 (Dez 2008) Florianópolis: UDESC/CEART, p. 75-83. (Anual ISSN 1414-5731).

KOUDELA, Ingrid Dormien. Jogos Teatrais. - 4. ed. - São Paulo: Perspectiva, 1998.

LEITE, Vilma Campos dos Santos. Jogo teatral e a criação literária. In: FLORENTINO, Adilson; TELLES, Narciso (orgs.). Cartografias do ensino do teatro. Uberlândia: EDUFU, 2009. 
PUPO, Maria Lúcia de Souza Barros. Entre o Mediterrâneo e o Atlântico: uma aventura teatral. São Paulo: Perspectiva, 2005.

RYNGAERT, Jean-Pierre. Jogar, representar: práticas dramáticas e formação. São Paulo: Cosac Naify, 2009.

SANTA Catarina, Secretaria de Estado da Educação e do Desporto. Proposta Curricular de Santa Catarina: Educação Infantil, Ensino Fundamental e Médio: Formação docente para educação infantil e séries iniciais. Florianópolis: COGEN, 1998.

SCHRAMM, Marilene de Lima Körting; CABRAL, Rozenei Maria Wilvert. Arte na Escola: um olhar sobre a história, limites e desafios da formação continuada e midiateca. In: SILVA, Neide de Melo Aguiar; RAUSCH, Rita Buzzi (orgs.). Extensão universitária: movimentos de aproximação entre sociedade e universidade. Blumenau: Edifurb, 2010.

SPOLIN, Viola. Jogos teatrais na sala de aula: um manual para o professor. São Paulo: Perspectiva, 2008.

MARQUES, Isabel. Dançando na escola. 3 ed. São Paulo: Cortez, 2006. 